\title{
1 Polyclonal infection as a new scenario in Mycobacterium caprae epidemiology
}

3 Ana C. Reis ${ }^{1,2,3}$, Teresa Albuquerque ${ }^{1}$, Ana Botelho ${ }^{1}$, Mónica V. Cunha ${ }^{1,2,3^{*}}$

4

$5 \quad{ }^{1}$ INIAV, IP- National Institute for Agrarian and Veterinary Research, Av. da República, Quinta do 6 Marquês, Edifício Principal, Piso 1, 2780 -157 Oeiras, Portugal.

$7 \quad{ }^{2} \mathrm{cE} 3 \mathrm{c}$ - Centre for Ecology, Evolution and Environmental Changes, Faculdade de Ciências da 8 Universidade de Lisboa, Edifício C2, $4^{\circ}$ Piso, Campo Grande, 1749-016 Lisboa, Portugal.

$9 \quad{ }^{3}$ BioISI - Biosystems \& Integrative Sciences Institute, Faculdade de Ciências da Universidade de 10 Lisboa, Campo Grande, 1749-016 Lisboa, Portugal.

$12 *$ Corresponding Author:

13 Mónica V. Cunha, PhD. Address: INIAV, IP - Av. da República, Quinta do Marquês, Edifício 14 Principal, Piso 1, 2780 -157 Oeiras, Portugal. monica.cunha@iniav.pt; Phone: +351 252660600

16 How to cite this article: Ana C. Reis, Teresa Albuquerque, Ana Botelho, Mónica V. Cunha. 17 Polyclonal infection as a new scenario in Mycobacterium caprae epidemiology. Vet Micr. 240, 18108533 (2020) https://doi.org/10.1016/j.vetmic.2019.108533

DOI: $10.1016 /$ j.vetmic.2019.108533 


\section{$21 \quad$ Highlights}

22 - M. caprae (n=55) genotyping over 12-year period revealed SB0157 and 24 MIRU-VNTR types.

23 - Fine-scale discrimination of isolates supports clonal structure and expansion of founder.

24 - Adaptive genotypic divergence of $M$. caprae paves the way for sympatric speciation.

25 - Unprecedented intra-host microevolution was detected at MIRU4 in over 20\% animals.

26 - Studies needed to evaluate functional implications of in vivo M. caprae parallel evolution.

27 
29 Portugal is one of the European Union (EU) countries with an ongoing eradication program for tuberculosis (TB) in cattle, which does not include systematic goat testing. However, surveillance in small ruminants is increasingly important, since goat and sheep can harbour Mycobacterium caprae and be an infection source to cattle with impact in the success of bovine TB control. Furthermore, the information regarding the epidemiology and biology of $M$. caprae is quite limited comparing to the cognate bovine-adapted ecotype, $M$. bovis.

In this work, we applied spoligotyping and MIRU-VNTR (Mycobacterial Interspersed $\underline{\text { Repetitive }}$

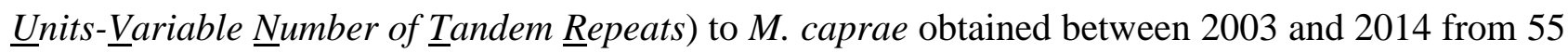
animal hosts, including goat $(n=29)$, cattle $(n=21)$, sheep $(n=1)$ and wild boar $(n=4)$ from Portugal. The molecular analysis revealed a unique spoligotyping pattern (SB0157) and 24 MIRU types. Genotyping of serial $M$. caprae from herds with recurrent outbreaks enabled fine-scale discrimination of epidemiologically related isolates, supporting a clonal structure in Portugal and denoting the emergence of clonal diversity at the herd level, more apparent for MIRU4. Results suggest a founder effect and adaptive genotypic divergence, paving the way for sympatric speciation.

Double allele findings at MIRU4 in over $20 \%$ of infected animals indicates that co-infection and in vivo microevolution are frequent events in the goat-adapted ecotype. While polyclonal infection appears to be commonin $M$. caprae epidemiology, the significance of subtle genotypic variations remains to be disclosed at the functional level, namely at the interface with the host, to expand knowledge on the epidemiological scenario of this neglected ecotype.

49 Keywords: Mycobacterium caprae; animal tuberculosis; spoligotyping; VNTR; clonal diversity; 50 polyclonal infection 


\section{Introduction}

52

53

54

55

56

57

58

59

60

61

62

63

64

65

66

67

68

69

70

71

72

73

Mycobacterium caprae (M. caprae) is a member of Mycobacterium tuberculosis complex (MTBC)

(Aranaz et al., 2003), a group of eleven host-adapted ecotypes, responsible for causing tuberculosis (TB) in different mammal species (Hershberg et al., 2008; Smith et al., 2006; Dippenaar et al., 2015; Clarke et al., 2016 ).

M. caprae was originally described as the causative agent of TB in goats (Aranaz et al., 2003). However, this pathogen has been isolated from other domestic (cattle, sheep, swine) and wildlife (red deer, wild boar and red fox) species, suggesting that its host specificity is apparent and that crossspecies transmission is more relevant than previously acknowledged (Aranaz et al., 2003, Rodríguez et al., 2011). With few exceptions, M. caprae has mainly been reported in European countries, mostly from the central and south continental regions, where goat is often managed as a species of economic interest to the traditional cheese, meat and whool industry. In Portugal, $M$. caprae represents ca. $4 \%$ of TB breakdowns (Matos et al., 2010, Cunha et al., 2012). In bordering country Spain, it represents 7.4\% (Rodríguez et al., 2011), while in Italy it is responsible for over $10 \%$ of TB outbreaks in cattle herds (Chiari et al., 2014). There have been some studies reporting $M$. caprae infection in red deer (Cervus elaphus) (Rodríguez et al., 2011; Schoepf et al., 2012) and wild boar (Sus scrofa) (Rodríguez et al., 2011; Cunha et al., 2012; García-Jiménez et al., 2012), mainly from Spain and countries with Alpine wildlife habitats.

M. caprae has also been linked with TB in humans, with cases reported in Spain, Germany and Croatia (Cvetnic et al., 2007, Kubica et al., 2003, Rodríguez et al., 2009). As with M. bovis, the consumption of unpasteurized dairy products and direct close contact with diseased animals have been attributed as potential sources of infection (Cvetnic et al., 2007).

Portugal, Spain, the United Kingdom, Austria, Ireland and Italy, are the European Union (EU) countries with an ongoing EU-financed TB eradication program in cattle herds. At present, EU regulations require TB surveillance and testing in dairy non-bovine species (Regulation 853/ 2004 of the European Council, section IX, Chapter I), however not all of the aforementioned countries 
currently have a specific eradication program for TB in goats. Austria have included in their surveillance shemes goat flocks that are in close contact with cattle, while in Spain these schemes are only applied to regions with a high density of goat flocks, such as Castilla y León, Murcia, Andalucía and Islas Canarias (Bezos et al., 2014).

TB surveillance in small ruminants is essential due to the risk of raw milk contamination and the potential subsequent public health effects. Both sheep and goat can harbor M. caprae or M. bovis [Matos et al., 2010; Muñoz-Mendonza et al. $(2012,2016)]$ and may be a source of infection to other small ruminants and also to cattle when managed in mixed species farms, jeopardizing the accomplishments of costly bovine TB eradication programs. The detection of infected animals is thus key for the effectiveness of control programs, however there is a lack of standard criteria to implement the intradermal tuberculin testing in goats, and certain intrinsic methodological aspects, as the site of injection or the interpretation criteria of test results, vary across and within countries (Pesciaroli et al., 2014). This situation leads to the application of these tests following the standards developed for cattle, which may misguide result interpretation and mislead infection management (Bezos et al., 2011; Bezos et al., 2012). Moreover, TB-compatible lesions in small ruminants are more rarely detected at slaughterhouses due to lower awareness and less exhaustive meat inspection procedures than those commonly carried out for cattle (Bezos et al., 2012a).

Despite the relevance of $M$. caprae as a TB-causing agent in goats, sheep, as well as cattle, diagnosis accuracy of related infections and population structure of the microorganism in domestic and wild animals have been poorly studied, in contrast to $M$. bovis. However, the fine discrimination of $M$. caprae isolates is key to understand the infection source and transmission pathways, as well as to apprehend the intrinsic biology of this pathogen. This knowledge may contribute to re-define or adjust TB eradication programs since, despite all efforts, the disease endures in the Mediterranean and is a re-emergent problem in central Europe (Ghielmetti et al., 2017, Gormely et al., 2014). In this context,

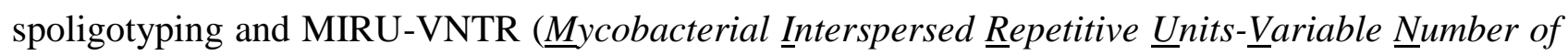
Tandem Repeats) typing have become common genotyping tools to characterize both $M$. bovis and 
M. caprae isolates. While commonly used alone in the recent past for epidemiological surveillance, spoligotyping has limitations due to homoplasy and the inability to distinguish mixed infections or clonal variants, since a unique spoligotype profile would be generated due to overlapping hybridization patterns. In contrast, MIRU-VNTR typing examines the copy number of tandem repetitions in polymorphic loci, potentially enabling the identification of concomitant allelic profiles, and, thus, assessment of mixed infections in the case of clearly distinct fingerprints.

Considering: 1) the circulation of $M$. caprae within TB maintenance community (goat, sheep, cattle), affecting species of economic interest in continental Europe, 2) its emerging importance to cases of zoonotic TB in humans, and 3) the lack of information regarding its epidemiology, population structure and genome diversification, our work envisaged the systematic molecular analysis of $M$. caprae isolates, both at the country and herd levels, in order: (i) to assess the reliability or limitations of spoligotyping and MIRU-VNTR for epidemiological investigation when $M$. caprae is involved; (ii) to enable fine-scale spatiotemporal discrimination of $M$. caprae isolates; (iii) to evaluate the occurrence of mixed infections; (iv) to appraise the emergence of clonal diversification. The genotyping data described and analysed as a whole in this report were obtained on several instances during the period 2003-2014, as indicated below.

\section{Materials and Methods}

\subsection{Bacterial isolates origin and molecular identification}

The M. caprae isolates under analysis in this study were obtained between 2003 and 2014 from tissue samples of 55 animals, namely goat (Capra aegagrus hircus) (n=29), cattle (Bos taurus) (n=21), sheep (Ovis aries) $(\mathrm{n}=1)$ and wild boar (Sus scrofa) $(\mathrm{n}=4)$ (Supplementary Table 1).

This 12-year molecular analysis concerns three periods: period 1 [(2003-2006), including genotyping results from Duarte et al. (2010)], period 2 [(2007-2008), including genotyping results from Cunha et al. (2012)], and period 3 (2009-2014, original data from this study). Data from Duarte et al. (2010), includes ten M. caprae isolates from seven goats from Beja, two bovines from Braga and one wild boar from Castelo Branco. Information from Cunha et al. (2012) increased previous data, adding nine 
M. caprae isolates from five goats and one bovine from Bragança, two bovines from Aveiro and wild boar from Castelo Branco.

The animal samples (lung and mediastinal, mesenteric, pre-scapular, popliteal, and/or retropharyngeal lymph nodes) originated from sanitary slaughter after positive intradermal testing or from routine meat inspection. Tissue samples from each animal were pooled and processed in a biosecurity level 3 facility at INIAV IP (National Institute for Agrarian and Veterinary Research, Portugal), according to the OIE Manual for Terrestrial Animals, with the technical specificities detailed in Cunha et al. (2012). Smears from homogenate sediment were prepared and stained by the Ziehl-Neelsen (ZN) technique to visualize acid-fast bacilli. Inoculation of homogenates on Stonebrink (Biogerm, Portugal) and Löwenstein-Jensen pyruvate (Biogerm, Portugal) solid media followed the guidelines for the diagnosis of bovine tuberculosis (OIE, 2008). To exclude cross contamination, a physiological saline blank per each processed batch was also inoculated into solid medium. Cultures were incubated for a minimum of 12 weeks at $37^{\circ} \mathrm{C}$ and slopes were examined for macroscopic growth every week during the incubation period. One to three colonies grown on selective slants were picked randomly and stained by ZN. Bacteria confirmed for acid-fast character were subsequently characterized. Cell cultures growing on slopes were suspended in TE buffer, heat killed, centrifuged and the crude supernatant containing nucleic acids was stored at $-20^{\circ} \mathrm{C}$. Species identification of presumptive mycobacterial isolates was performed by restriction fragment length polymorphism analysis of PCR- amplified $g y r B$ gene (PCR-REA) as described in Cunha et al. (2012) or using commercially available systems [GenoType Mycobacterium (Hain diagnostics, Germany)] according to manufacturer instructions. In all PCR batches, in addition to samples, positive controls (M. tuberculosis $\mathrm{H} 37 \mathrm{RV}$ and M. bovis $\mathrm{BCG}$ ) and a negative control (water) were included.

\subsection{Study area}

Twelve of the 18 districts (administrative level sampling unit) of mainland Portugal were represented in this study (Supplementary Fig. 1). Bragança (North-East) is the district with more M. caprae 
154

155

156

157

158

159

160

161

162

163

164

165

166

167

isolates $(n=21)$ and sampled host species (sheep, goat, cattle). Two M. caprae isolates were from cattle of the Azores islands.

\subsection{Epidemiological information of infected herds}

Basic life history traits, as gender and age, were only available for some of the domestic animals under analysis.

Epidemiological information on livestock, specifically previous history of TB in the herd, animal movement history and animal management conditions (herd type and dimension) was also only accessible for a subset of hosts.

\subsection{Anatomical localization and histological characteristics of TB-compatible lesions}

For histopathological examinations, animal samples were fixed in $10 \%$ buffered formalin and paraffin- embedded by standard procedures. Five micrometer-thick sections were stained with haematoxylin and eosin and examined using light microscopy. Microscopic lesions (data available for 20 animals only, from 2008 onwards) were histologically classified into three types according to lesion progression: type I- "caseous granulomatous lesions”, type II- "caseous granulomatous lesions with calcification" and type III- "caseous granulomatous lesions with cavitation".

\subsection{Spoligotyping and MIRU-VNTR analyses of $M$. caprae isolates}

Spoligotyping was performed according to Kamerbeek et al. (1997), with the modifications described by Botelho et al. (2015). The spoligotyping pattern was converted into a binary code of 43 digits that was checked against the international database Mbovis.org (http://www.mbovis.org/index.php).

Variable number tandem repeat analysis was performed using a previously established 8-loci MIRUVNTR set, whose allelic diversity was shown to be appropriate to study the epidemiological scenario in Portugal (Duarte et al., 2010): VNTR3232, ETR-A, ETR-B, ETR-C, QUB11a, QUB11b, MIRU26 and MIRU4. These loci were amplified by PCR using the primers and cycling conditions previously described by Cunha et al. (2012). Positive controls (DNA extracted from M. tuberculosis H37Rv and M. bovis $\mathrm{BCG}$ ) and a negative control (water) were included in all PCR assays. 
Amplicon size was estimated by electrophoresis in a 1.5\% agarose gel, prepared in Tris Buffer EDTA 1x. All electrophoretic runs were conducted in the same gel cast and tank, maintaining the same parameters ( $90 \mathrm{~V}$ for a period of 3 hours). The number of repeats in each amplified locus was attributed by correlation with the amplicon size according to previously published tables (Supply et al., 2006). Each MIRU-VNTR profile was nominated as a genotypic profile, and the profiles were grouped into MIRU types following Cunha et al. (2012). The genotypic profiles presented are joint results from this study (isolates from 2009 to 2014), Duarte et al. (2010) and Cunha et al. (2012) (Table 1). Amplification of double alleles at MIRU4 locus was confirmed at least in three independent PCR and electrophoresis experiments for each of the $12 M$. caprae TB cases wherein this situation was registered. Furthermore, the PCR amplification products corresponding to alleles 3 and 4 at MIRU4 from five randomly selected TB cases with two genotypic variants were run on agarose gel, the DNA fragments were excised, purified (QIAquick gel extraction kit; Qiagen, Hilden, Germany) and commercially sequenced (GATC Biotech, Germany). Original chromatogram files were inspected and reviewed. The resulting Fast Adaptive Shrinkage Thresholding Algorithm (FASTA) sequences were aligned in ClustalX 2.1, mapped against M. bovis AF2122 as reference, and the number of tandem repetitions confirmed in silico for each amplification product. For the 12 cases were these double alleles were detected, four additional loci (MIRU16, MIRU40, ETR-E and QUB26) were added to the initial panel of MIRU-VNTR loci to eventually improve discrimination (12-loci MIRUVNTR). These loci were amplified by PCR using the primers described by Supply et al. (2001) and Skuce et al. (2000), and the cycling conditions were the same as previously described for the other loci of the panel.

The discriminatory power (D) of MIRU-VNTR typing and the individual allelic diversity (h) of the loci panel tested was calculated as described by Hunter and Gaston (Hunter \& Gaston, 1988), using an online tool available on the website http://insilico.ehu.es (accessed on may 2019). The discriminatory power of the technique was calculated for complete genotypic profiles only.

\subsection{Phylogenetic analysis}


205 In order to study the phylogenetic relationships among $M$. caprae isolates, a minimum spanning tree 206 (MST) was generated building on MIRU types and using the MIRU-VNTRplus web application 207 available at http://www.miru-vntrplus.org (accessed on march 2019). The incomplete profiles (M117, 208 M117' and M119) were excluded from this analysis. The loci QUB11a and VNTR3232 are not 209 included in the standardized data sets of MIRU-VNTRplus and therefore were arbitrarily assigned to 210 database fields of standard loci.

$211 \quad$ 2.7. Statistical analysis

212 The Chi-square $(\alpha=0.05)$ test was used whenever appropriate to test statistical significance of several 213 associations. Contingency tables and tests were performed in IBM SPSS Statistics (version 24.0.0). 214 Results were considered to be significant if $\mathrm{p}<0.05$. 


\subsection{Epidemiological information of animals under analysis}

217 Regarding the basic life history traits of the animal population under analysis, 24 were female, nine 218 were male and for 22 gender was unknown; 60\% $(n=33)$ were less than 12 years old (Supplementary 219 Table 1).

220 Information regarding herd type (multiple versus single species) was available for 41 out of 51 $221(80.4 \%)$ domestic animals. In a minority of cases $(19.6 \%, n=8 / 41)$, herds were shared by more than 222 one animal species (Supplementary Table 1).

223 Herd dimension was registered for 35 animals (68.6\%) and classified into three types according to 224 size: type A, less than 50 individuals $(n=8 ; 23 \%)$; type $\mathrm{B}$, between 50 and $150(n=7,20 \%)$; and 225 type $\mathrm{C}$, more than 150 animals $(n=20 ; 57 \%)$. The majority of goat herds were type $\mathrm{C}$, whereas cattle herds were types A or B. Information about herd management (intensive or extensive) was available for $17(33.3 \%)$ animals; eleven $(64.7 \%)$ were in an extensive regime (Supplementary Table 1).

\subsection{Anatomical localization and histological characteristics of TB-compatible lesions}

In total, post-mortem macroscopic lesions compatible with TB were observed in 25 out of 55 screened animals (45.5\%), including 14 goats (48.3\%), six bovines (28.6\%), four wild boars and one sheep. Moreover, for 20 of these animals (from 2008 onwards) a histological description was also available. Type I lesions were present in five animals (7.3\%), type II in nine (16.4\%), and type III in six (10.9\%) (Supplementary Table 1).

Type I lesions were restricted to lung and mediastinal lymph nodes and type III lesions to lung. However, type II lesions were located in more anatomical regions, including lung and mediastinic, mesenteric and submaxillary lymph nodes (Supplementary Table 1).

3.3. Spoligotyping and multilocus variable number of tandem repeat analysis of $M$. caprae strains

Fifty-five culture-confirmed TB cases, confirmed by gyrB-REA and Genotype ${ }^{\circ}$ as $M$. caprae, were 
recovered from cultured microorganisms homogeneously generated SB0157 pattern, while 8-loci MIRU-VNTR could discriminate 67 genotypic profiles grouped into 24 MIRU types that were classified following the nomenclature adopted in Cunha et al. (2012) (Table 1). M. caprae strains with double alleles were subdivided in two genotypic profiles (i.e. MIRU types), one for each allele, that is why 67 genotypic profiles could be generated by 55 M. caprae isolates. Despite several attempts, lack of amplification of MIRU4 in three isolates hampered completion of three allelic profiles (M117, M117' and M119).

The overall discriminatory index of MIRU-VNTR was $\mathrm{D}=0.8856$. The allelic diversity of individual locus ranged from 0.0592 to 0.5509 , in decreasing order: VNTR $3232(h=0.5509)$, MIRU4 $(h=0.5441)$, ETR-A $(h=0.5061)$, QUB11b $(h=0.4885)$, QUB11a $(h=0.4283)$, MIRU26 $(h=0.2451)$, and ETR-B and ETR-C ( $h=0.0592)$.

\subsection{Detection of genotypic variants within the same host}

In $12 \mathrm{~TB}$ cases $(21.8 \%)$, infection with clonal variants was suspected due to the concomitant detection of two M. caprae genotypic profiles within the mycobacterial DNA recovered from the same animal. Polyclonal infection was suggested by the presence of double alleles (allele 3 or 4 , in all cases) exclusively in MIRU4, while in each of the additional seven loci only single alelles were detected

(Table 1). All cases of recovered DNA displaying double alleles in one locus that were suggestive of clonal microevolution from founder strain were retested on several occasions and the simultaneous presence of alleles 3 and 4 confirmed. The PCR amplification products of the DNA fragments corresponding to allele 4 and allele 3 of five randomly selected double allele findings were sequenced and the corresponding sequences were aligned and mapped on the sequence of MIRU4 from M. bovis AF2122. Two sequences of allele 3 were excluded due to poor quality. No nucleotide sequence polymorphisms between the $M$. bovis reference strain and the field strains were found at this locus (supplementary Figure 2). In all cases, the sequence of allele 4 differed exactly in one tandem repetition (77 bp) when compared with the sequence of allele 3, supporting the co-existence of double alleles. 
The profiles of these MIRU4 genotypic variants were distinguished into separate MIRU types: M132 and M133 (concomitantly isolated from 10 animals, cattle and goat), M134 and M135 (one bovine), and M136 and M137 (one goat) (Table 1).

In an attempt to further confirm that the genotypic profiles of the 12 cases with double alleles findings at MIRU4 locus did not differ in any other locus, the panel of MIRU-VNTR was increased from eight to twelve loci. The results obtained for MIRU16, MIRU40 and ETR-E were equal for all the cases under analysis, generating alleles 5, 1 and 4, respectively. Discrimination was achieved when adding QUB26 locus, with five DNA samples yielding allele 2 and seven generating allele 3. No double alelles were detected in this additional panel of four loci, supporting the original suspicion for the coexistence of clonal variants.

The genotypic variants with double allele findings were detected along the years [2008 (in one bovine), 2009 (one bovine), 2010 (eight goats, one bovine), 2012 (one goat) and 2013 (one goat)] in herds located in Bragança, Lisboa, Beja and Évora (Table 1). The proportion of animals putatively harbouring $M$. caprae clonal variants was statistically associated $(\mathrm{p}=0.038)$ with Bragança district. The influence of host species or time period on co-infection with clonal populations was found not to be statistically significant.

\subsection{Distribution of MIRU types by host}

284 The most common MIRU type was M132 (32.7\% of infected animals), which was detected either in animals ) simultaneously harbouring two genotypic profiles $(n=10)$ but also as a single infecting population $(n=8)$; following was M133 (detected only in animals with two $M$. caprae genotypic profiles, $n=10$ ), M137 (generated by one co-infecting genotypic profile, $n=1$; and single infected, $n=8$ ) and M69 (detected only in single infected, $\mathrm{n}=6$ ); four MIRU types clustered two genotypic profiles each (M70, M116, M118, M128), and the remaining types ( $n=15)$ were singletons, although it cannot be discarded that M117 and M117', for which MIRU4 allele could not be determined, might 
results obtained for MIRU40 and QUB26 were equal for all the cases under analysis (alleles 2 and 5, respectively). M117 and M117' yielded allele 5 and M119 the allele 4 in ETR-E while M119 had allele 4. No double alleles were detected in this additional panel of genotyped loci.

The genotypic profiles from goats $(n=38)$ were grouped into 11 MIRU types, M132 being the most common (31.6\%); cattle exhibited the highest diversity, with 24 genotypic profiles grouping into 15 MIRU types, of which M132 was also the most frequent; the single infected sheep also harboured M132; and the four wild boar M. caprae isolates generated three profiles. Four MIRU types were thus common to several host species: M70 to wild boar and cattle, M133 to goat and cattle, M132 to goat, cattle and sheep, and M137 was found in goat, cattle and wild boar (Table 1).

\subsection{Distribution of MIRU types by geographical location}

Among the 12 sampled districts of mainland Portugal, Bragança and Beja yielded more than half of

the $M$. caprae genotypic profiles under study and higher diversity of MIRU types (eight and seven, respectively). Four MIRU types were common to different geographical locations: M70 is present in Castelo Branco and Braga; M132 is widespread in the north (Bragança, Vila Real and Viana do Castelo) and was also detected in Lisbon; M133 was frequent in Bragança herds and also found in Lisbon; and M137 is dispersed from north to south, in a total of seven districts (Vila Real, Guarda, Viseu, Castelo Branco Lisboa, Portalegre and Évora). Two singletons were isolated from cattle of the Azores islands (Table 1).

\subsection{Clonal complexes defined by MIRU types}

A minimum spaning tree (MST) was built with the 64 complete genotypic profiles, grouped in 21 MIRU types, using the single locus variant (SLV) analysis, grouping the MIRU types into three clonal complexes (CC, named CC1 to CC3), with the exception of M116, M118, M122, M120 and M140

316 Clonal complex 1 is dispersed from north to south of mainland Portugal, in a total of ten districts;

317 CC2 is present in six districts; and CC3 is restricted to Beja and Azores islands and exclusively found 318 in cattle. Beja is the single district with MIRU types from the three clonal complexes (Table 1). 
A detailed inspection was performed for Bragança and Beja districts, as these were the districts with more TB breakdowns and M. caprae isolates, enabling a spatiotemporal analysis. For Bragança, MST drawn for complete MIRU types, grouped one of five haplotypes in CC1 and two in CC2 (Fig. 1b). In Beja, the isolates were grouped within one of the three clonal complexes (Fig. 1c): genotypic profiles from herd $\mathrm{BJ} 1$ are clustered in $\mathrm{CC} 1$; from $\mathrm{BJ} 2, \mathrm{BJ} 3$ and $\mathrm{BJ} 4$ herds in $\mathrm{CC} 3$; and from $\mathrm{BJ} 5$, in CC2. Moreover, a temporal separation was evidenced, with isolates from 2003 and 2004 grouping in CC1, and from 2009 and 2010 in CC2 or CC3 (Fig. 1c).

The Chi-square test was used to compare the proportion of isolates, with complete genotypic profiles, grouped by clonal complexes, across host species, geographic location and year (Supplementary table 2a to $2 \mathrm{~d})$. CC3 was found to be associated to cattle $(\mathrm{p}<0.01)$.

Geographic location was analysed by district and NUTS II regions: North (Viana do Castelo, Braga, 330 Porto, Vila Real and Bragança districts), Center (Aveiro, Viseu, Guarda, Castelo Branco, Leiria, 331 Santarém and Coimbra districts), Alentejo (Portalegre, Évora, Beja and Setúbal ditricts) and Azores islands. The analysis of proportion of clonal complexes per NUTS indicated a significant association of $\mathrm{CC} 1$ with Alentejo, CC2 with North region and CC3 with Alentejo and Azores islands. When this analysis was stratified to the district level, a significant association was registered for CC1 with Évora, CC2 with Bragança and CC3 with Beja $(\mathrm{p}<0.01)$.

Three time periods were analysed, considering the epidemiological situation of TB in Portugal: between 2003 and 2006, in which herd prevalence steadly decreased; between 2007 and 2010, in which herd prevalence raised more than 3-fold; and between 2011 and 2014, in which there was substantial reinforcement of ante-mortem and post-mortem vigilance in livestock and carcass examination of hunted big game became mandatory in specific regions. Statistical significant associations $(\mathrm{p}<0.01)$ between time period and clonal complex were confirmed in the case of $\mathrm{CC} 1$ 330 for the periods 2003-2006 and 2011-2014. 
344 Histological description of TB compatible lesions was available for 20 animals, including three males 345 and 14 females. Males were less than 2 years old and presented type I or type II lesions. Females' age 346 ranged from 1 to 10 years old and the three types of lesion progression were documented 347 (Supplementary Table 1).

348 M. caprae strains isolated from animals with type I lesions belong to M118, M128 or M132 MIRU 349 types and CC2 or CC3; animals with type III lesions exhibited CC1 or CC2 M. caprae isolates with 350 M132, M136 or M137 MIRU types. A wider strain variability was registered in animals with type II 351 lesions: M122, M131, M132, M133, M137 or M139, distributed across the three clonal complexes. 352 MIRU types M132 and M137 were common to lesion types II and III (Table 1; Supplementary Table $3531)$.

354 Heterogenous outbreaks were common in herds with recurrent infection along two or more years.

\subsection{Epidemiological tracing within and between herds}

356

Although information about goat and sheep movement was not available, it was possible to obtain data concerning cattle movement and previous history of $\mathrm{TB}$ in infected herds, enabling the assessment of the transmission routes based on M. caprae genotypic profiles.

For eight of the 21 cattle under study, no movements were recorded prior to slaughter. For most of the remaining animals, the documented movements occurred within the same district. Epidemiological relationships were established among four infected cattle (B7, B8, B9, B10, B12) that circulated up to a 10-year timespan in five herds (BJ2-BJ7) from Beja, sometimes in overlapping periods (Supplementary Fig. 3). It is worthwhile noticing that the MIRU types generated by those cattle isolates were M128, M129, and M131, which are SLVs within CC3, and M134 and M135 (included in $\mathrm{CC} 2$ ), which belong to the same animal.

Eventhough no records of animal movements were available for goat, M132 was confirmed in at least four herds from Bragança. It cannot be excluded that this strain additionally infected other farms in the region, since for seven animals herd identification was not available (Table 1). Moreover, two cattle from different herds in the same region also harboured M132. 


\section{Discussion}

371 Spoligotyping and MIRU-VNTR typing data have been used over the years to study the structure and diversity of M. bovis population in Portugal, which is the prevalent ecotype of animal TB in Portugal. Although the number of herds which were sampled several times over this study period is limited (3/28) and information about animal movement was only available for some cattle herds, by assessing the genetic relationships among isolates covering a 12-year surveillance period, the present study was an opportunity to refine the understanding of the epidemiology of M. caprae infections, which are much less common across Europe. Irrespective of the host species and geographical region (mainland Portugal or Azores islands), all $M$. caprae isolates homogeneously generated spoligotyping profile SB0157. This observation is consistent with previous studies (Duarte et al., 2010; Cunha et al., 2012), confirming that SB0157 remains the sole $M$. caprae spoligotyping pattern ever recorded in Portugal and continuing to be dominant in Iberia, since it is also the most commonly detected profile in bordering Spain (Rodríguez et al., 2011). However, in Spain 15 different spoligotyping patterns for M. caprae strains were already reported (Rodríguez et al., 2011; García-Jiménez et al., 2016). Also in other countries where M. caprae is present, usually several spoligotypes are detected, which makes the epidemiological situation in Portugal quite singular.

387 Since spoligotyping did not discriminate infecting strains, MIRU-VNTR typing was thereafter performed to assess intra-herd and intra- and inter-host specific genotypes, further discriminating the M. caprae population into 24 MIRU types. Regrettably, the lack of amplification of MIRU4 in three M. caprae strains hampered completion of three allelic profiles not included in the MST analyses. Lack of amplification of MIRU4, but also of VNTR3232, MIRU16 and MIRU23, has been reported by other colleagues, when applying MIRU-VNTR typing for molecular characterization of $M$. caprae strains (Navarro et al., 2014; Prodinger et al., 2005). This situation might have been due to either variability in the primer regions or the absence of the locus altogether. Repeated but failed attempts to amplify this locus suggest that the latter hypothesis is plausible. The overall discriminatory index 
$(\mathrm{D}=0.8856)$ attained with MIRU-VNTR analyses indicated a good resolution of the selected eight

397 loci panel to characterize this $M$. caprae population. ETR-B and ETR-C $(h=0.0592)$ were the least 398 polymorphic, which is in agreement with previous data from animal TB cases in Portugal. In contrast, 399 earlier studies from the country (Duarte et al., 2010, Cunha et al., 2012) pointed out QUB11a, followed by ETR-A and MIRU26, as the most polymorphic, while in this work VNTR3232 revealed as the most discriminatory for $M$. caprae ecotype. Down-sizing the allele diversity analysis for the three administrative regions with more $M$. caprae infection cases (Évora, Bragança, and Beja), 403 discriminatory power of MIRU-VNTR ranged from 0.7 to 0.795 , respectively. In Évora, discrimination of the three MIRU types recorded from 2010 to 2013, was achieved with loci QUB11a and MIRU4 (one repeat difference in each). The number of occurrences of a given allele for the selected loci panel was equal or superior to 24 (out of 30) in the case of Bragança herds, the exception being MIRU4, for which a superior diversity was found related to the discovery of intra-host genotypic variants. Even with recurrent breakdowns from 2007 to 2014, an increase in allelic diversity was, in general, not detected over time in Bragança. These results indicate that, within these regions, breakdowns were homogeneous and epidemiologically related with persistence of a clone in the region, as the genotypic profiles recorded in Évora were collapsed into $\mathrm{CC} 1$ and the majority recorded in Bragança belong to $\mathrm{CC} 2$. In Beja, a progressive expansion of allelic diversity, related to 413 one to four repetition losses, could be registered from 2003 to 2010 and a temporal divison was clear, 414 with M. caprae strains from 2003 and 2004 grouping in CC1 and from 2009 onwards in CC2 and 415 CC3. Results for this region suggest multiple sources of infection, together with microevolution of a 416 persistent, recrudescent, clone

417 A comprehensive analysis of multilocus genotypes suggests that, eventhough 24 MIRU types could 418 be distinguished from the 67 genotypic profiles obtained from $55 M$. caprae strains, most genotypes 419 (16 out of 21) developed from single or double locus variations upon basal types (Fig. 1a), suggesting 420 a clonal structure and supporting that the genetic heterogeneity of $M$. caprae outbreaks under scrutiny 421 is apparent and consistent with the expansion of a founder strain. Single locus variant analysis 
422

423

424

425

426

427

428

429

430

431

432

433

434

435

436

437

438

439

440

441

442

443

444

445

446

447

evidenced three complexes, with significant statistical association of CC1 to Alentejo, CC2 with Northern region and CC3 with Alentejo and Azores. Analysis of the available epidemiological information, including animal movement that confirmed regular cattle contacts across farms in Alentejo, suggest epidemiological linkage of several outbreaks (re)occurring along a temporal gradient. Our assumptions particularly gain strength in Bragança district wherein most outbreaks and recurrent breakdowns at single herds were genotipically related to a clonal population and M132 was recorded in closely located goat and sheep herds in different time periods. Moreover, two genotypic profiles (M132 and M133) were recorded in the same year in nine animals. Mounting to this complex scenario, numerous $M$. caprae infected hosts were concomitantly infected with two genotypic profiles, whose MIRU types were only distinguished by differences in MIRU4 locus. The spatiotemporal occurrence and frequency of these clonal variants was remarkably high, with $22 \%$ of the screened population being affected, and with M132 and M133 as the most frequent genotypic variants. The topology of the MST also leads us to conjecture the presence of an archetypical founder clone circulating in mainland Portugal, with spatiotemporal information reinforcing the notion of this clone possibly underwenting sympatric speciation, mirrored by microevolutionary events associated to the loss of one to two tandem repeats in a single locus. The genotypes of these SLVs strains possibly reflect genomic adaptation events underlying the expansion of the founder strain to different animal species (e.g. CC3 was exclusively found in cattle) and epidemiological scenarios, highlighting the complex transmission dynamics of a multi-host system that sustains $M$. caprae maintenance and spillover in this study area.

The occurrence of double bands in MIRU4, as observed in 12 M. caprae infected animals, hint to coinfection with different strains, although it could not be determined if it was acquired on a single timepoint or on separate occasions, or if it was due to a microevolutionary event on founder strain. However, simultaneous infection of nine animals with two genotypes each seems highly unlikely as does transmission of co-infecting strains. Results rather support the idea of microevolution of an infecting strain inside the host. Application of 12-loci MIRU-VNTR to mycobacterial DNA recovered 
from these animals showed that, in each animal, the two genotypic profiles only differ in one marker, while DNA sequencing showed that differences between alleles are exclusively related to an INDEL of a tandem repetition, reinforcing the notion of microevolution pressure upon MIRU4. Polyclonal infection markedly differs from co-infection with different strains acquired on a single timepoint or on separate occasions, since these would clearly yield distinct DNA fingerprints. So, our observations are afore consistent with the initial infecting strain undergoing genetic changes, possibly to face challenges at the interface with the host, resulting in the expansion of genotypes and possibly phenotypes. Whether this clonal expansion has influenced virulence or immune evasion is yet unknown, but given the frequency that we registered this phenomenon, we are persuaded by the idea of functional implications arising from microbial genome modulation. No clear trend of virulence increase (using lesion severity of infected animals as proxy) could be inferred in farms with long term and recurrent infections, since our sampling size is limited to assess these trends.

The proportion of animals harbouring clonal $M$. caprae isolates was significantly associated with Bragança district but the influence of host species or time span of herd infection was found not to be statistically significant.

Reports on the emergence of clonal variants in M. tuberculosis infection are sporadic in the literature (Al-Hajoj et al., 2010, Shamputa et al., 2006) and similar studies on animal-adapted ecotypes are scarcer, with the majority being restricted to M. bovis (Gormley et al. 2014, Navarro et al., 2016, Ghielmetti et al., 2017). Here we confirm that parallel evolution related to tandem repeat repeat loss (or gain) is not restricted to M. bovis, being a frequent event in the goat host and occurring both in chronically infected- and also on occasionally-infected herds. Whether intra-host parallel evolution also occurs in other non-SB157 M. caprae isolates or is confined to this specific lineage circulating in Portugal is unknown.

471 MIRU4 is found within the intergenic region of an operon encoding in M. bovis and M. tuberculosis a mycobacterial two component system (Supply et al., 1997). To elaborate on the potential genomic impact resulting from pressure upon MIRU4, we mapped this locus on M. caprae Allgaeu and also 
on M. bovis AF2122 and M. tuberculosis H37Rv genomes (NZ_CP016401.1, NC_002945.4 and NC_000962.3, respectively). In all these, MIRU4 was located in a region with homology with the hydroxyl terminal moiety encoding the ATP- binding site of senX3, a putative two component sensor histidine kinase that is involved in the phosphorylation of regX3. MIRU4 region also overlapps the 5' region, within the phosphoacceptor site, of a probable DNA-binding response regulator presumed to be involved in signal transduction and apparently common to all MTBC members. Since bacterial two-component system are important in signal transduction, allowing microorganisms to adapt physiological responses to changes in the surrounding environment, it is most likely that any nucleotide loss or gain in these regions could trigger downstream effects, either at the transcriptional and/or translational level, with functional implications.

In vivo microevolution and co-infection has probably gone underdetected in $M$. caprae infections since first line molecular epidemiology studies are mainly based on spoligotyping and the procedure of genotyping isolates from DNA recovered from a pool of tissues of a single animal is common, originating overlapping fingerprints that cannot be distinguished in the case of co-infection. In this matter, MIRU-VNTR typing may be more robust to differentiate both mixed or clonal populations, although homoplasy has also been reported for MIRU-VNTR.

Results from this work do reinforce the complexity of $M$. caprae epidemiology. More in-depth genomic analyses enabled by last generation high-throughput sequencing platforms may provide further insight into ecological processes underlying transmission and host adaptation. Functional studies in $M$. caprae are also demanded to enable integration of evolutionary, ecological, and functional perspectives able to inspire effective surveilance and control measures in goat herds, including development of relevant legislation, as currently available for $M$. bovis and cattle infections.

\section{Acknowledgements}

We are indebted with the National Veterinary Authority [DGAV (DSSPA)], Yolanda Vaz, Isabel Rolão Preto, Heloísa Almeida Silva, and DGAV collaborators in general, for kindly providing 
500 epidemiological information and baseline data on cattle movements and small ruminant farms. The 501 technical assistance of Celeste Matos, Alice Batalha, Ana Canto, Madalena Monteiro, Paulo Carvalho 502 and Paula Mendonça, in the context of routine animal TB laboratorial diagnosis is gratefully 503 acknowledged.

504 6. Funding

505 This work was funded by Programa Operacional de Competitividade e Internacionalização (POCI) 506 (FEDER component), Programa Operacional Regional de Lisboa, and Fundação para a Ciência e a 507 Tecnologia (FCT), Portugal, in the scope of projects "Colossus: Control Of tubercuLOsiS at the 508 wildlife/livestock interface uSing innovative natUre-based Solutions" (ref. POCI-01-0145- FEDER509 029783), MyPATH (ref. PTDC/CVT/117794/2010) and strategic funding to cE3c and BioISI 510 Research Units (UID/BIA/00329/2019 and UID/Multi/04046/2019). Financial support from 511 Programa de Desenvolvimento Rural, FEADER and P2020 is also gratefully acknowledged in the 512 scope of project Alliance-i9-Caça (ref. PDR2020-2024-049959). ACR was supported by FCT 513 through a doctoral grant in the framework of the Applied and Environmental Microbiology Doctoral 514 Program (PD/BD/128031/2016).

515 7. Conflict of Interest Statement: The authors declare that no competing interests exist. 516 


\section{References}

518 Al-Hajoj, S., Akkerman, O., Parwati, I., al-Gamdi, S., Rahim, Z., van Soolingen, D., van Ingen, J., 519 Supply, P., van der Zanden, A., 2010. Microevolution of Mycobacterium tuberculosis in a $520 \quad$ tuberculosis patient. J. Clin. Microbiol. 48, 3813-6.

521 Aranaz, A., Cousins, D., Mateos, A., \& Domínguez, L., 2003. Elevation of Mycobacterium tuberculosis subsp. caprae Aranaz et al. 1999 to species rank as Mycobacterium caprae comb. nov., sp. nov. Int J Syst Evol Microbiol., 53, 1785-1789.

Bezos, J., Álvarez, J., de Juan, L., Romero, B., Rodríguez, S., Castellanos, E., Saéz-Llorente, JL., Mateos. A., Domínguez, L., Aranaz, A., 2011. Factors influencing the performance of an interferon- $\gamma$ assay for the diagnosis of tuberculosis in goats. Vet. J. 190, 131-135.

Bezos, J., Álvarez, J., Romero, B., Aranaz, A., de Juan, L., 2012. Tuberculosis in Goats: Assessment of Current in Vivo Cell-Mediated and Antibody-Based Diagnostic Assays. Vet. J. 191, 161-65.

Bezos, J., Marqués, S., Álvarez, J., Casal, C., Romero, B., Grau, A., Mínguez. O., Domínguez, L., de Juan. L., 2014. Evaluation of single and comparative intradermal tuberculin tests for tuberculosis eradication in caprine flocks in Castilla y León (Spain). Res. Vet. Sci. 96, 39-46.

Botelho, A., Canto, A., Leão, C., Cunha, MV. 2015. Clustered regularly interspaced short palindromic repeats (CRISPRs) analysis of members of the Mycobacterium tuberculosis complex. Methods Mol Biol.

Chiari, M., Zanoni, M., Alborali, LG., Zanardi, G., Avisani, D., Tagliabue, S., Gaffuri, A., Pacciarini, (Cervus elaphus) in Italy. J Wildl Dis. 50, 330-33.

Clarke, C., van Helden, P., Miller, M., Parson, S., 2016. Animal-adapted members of the Mycobacterium tuberculosis complex endemic to the Southern African subregion. J S Afr. Vet. Assoc. 26. doi: 10.4102/jsava.v87i1.1322. 
541 Cunha, MV., Matos, F., Canto, A., Albuquerque, T., Alberto, JR., Aranha, JM., Vieira-Pinto, M., 542 Botelho, A., 2012. Implications and Challenges of Tuberculosis in Wildlife Ungulates in Portugal: 543 A Molecular Epidemiology Perspective. Res. Vet. Sci. 92, 225-35.

544 Cvetnic, Z., Katalinic-Jankovic, V., Sostaric, B., Spicic, S., Obrovac, M., Marjanovic, S., Benic, M., 545 Kirin, BK., Vickovic, I., 2007. Mycobacterium caprae in Cattle and Humans in Croatia. Int J $546 \quad$ Tuberc Lung Dis. 11, 652-58.

547 Dippenaar, A., Parsons, S. D. C., Sampson, S. L., Van Der Merwe, R. G., Drewe, J. A., Abdallah, A. 548 M., Siame, KK., Gey van Pittius, NC., van Helden, PD., Pain, A., Warren, RM., 2015. Whole 549 genome sequence analysis of Mycobacterium suricattae. Tuberculosis. 95, 682-688.

550 Duarte, EL., Domingos, M., Amado, A., Cunha, MV., Botelho, A., 2010. MIRU-VNTR typing adds 551 discriminatory value to groups of Mycobacterium bovis and Mycobacterium caprae strains defined 552 by spoligotyping. Vet Microbiol. 143, 299-306.

553 García-Jiménez, WL., Benítez-Medina, JM., Fernández-Llario, P., Abecia, JA., García-Sánchez, A., 554 Martínez, R., Risco, D., Ortiz-Peláez, A., Salguero, FJ., Smith, NH., Gómez, L., Hermoso-de555 Mendoza, J., 2012. Comparative Pathology of the Natural Infections by Mycobacterium bovis and 556 by Mycobacterium caprae in Wild Boar (Sus scrofa). Transbound Emerg Dis. 60, 102-9.

557 García-Jiménez, W., Cortés, M., Benítez-Medina, J., Hurtado, I., Martínez, R., García-Sánchez, A., 558 Risco, D., Cerrato, R., Sanz, C., Hermoso-de-Mendoza, M., Fernández-Llario, P., Hermoso-de559 Mendoza, J., 2016. Spoligotyping diversity and 5-year trends of bovine tuberculosis in 560 Extremadura, outhern Spain. Trop Anim Health Prod. 45, 1533-40.

561 Ghielmetti, G., Scherrer, S., Friedel, U., Frei, D., Suter, D., Perler, L., Wittenbrink, MM., 2017. 562 Epidemiological tracing of bovine tuberculosis in Switzerland, multilocus variable number of 563 tandem repeat analysis of Mycobacterium bovis and Mycobacterium caprae. PLoS One. 21;12(2): $\mathrm{e} 0172474$. 
565 Gormley, E., Corner, LAL., Costello, E., Rodriguez-Campos, S.,2014. Bacteriological Diagnosis and 566 Molecular Strain Typing of Mycobacterium bovis and Mycobacterium caprae. Res. Vet. Sci. 97, $567 \quad 30-43$.

568 Hershberg, R., Lipatov, M., Small, P. M., Sheffer, H., Niemann, S., Homolka, S., Roach, JC., Kremer, 569 K., Petrov, DA., Feldman, MW., Gagneux, S., 2008. High Functional Diversity in Mycobacterium 570 tuberculosis Driven by Genetic Drift and Human Demography. PLoS Biology. 6, e311.

571 Hunter, P \& Gaston, M.,1988. Numerical Index of the Discriminatory Ability of Typing Systems: an 572 Application of Simpson's Index of Diversity. J Cli Microbiol. 26, 2465-66.

573 Kamerbeek, J., Schouls, L., Kolk, A., van Agterveld, M., van Soolingen, D., Kuijper, S., Bunschoten, A., Molhuizen, H., Shaw, R., Goyal, M., van Embden, J., 1997. Simultaneous Detection and Strain Differentiation of Mycobacterium tuberculosis for Diagnosis and Epidemiology. J Cli Microbiol. 35,907-14.

Kubica, T., Rüsch-Gerdes, S., Niemann, S., 2003. Mycobacterium bovis subsp. caprae caused onethird of human M. bovis-associated tuberculosis cases reported in Germany between 1999 and

Matos, F., Cunha, MV., Canto, A., Albuquerque, T., Amado, A., Botelho, A., 2010. Snapshot of Mycobacterium bovis and Mycobacterium caprae infections in livestock in an area with a low incidence of bovine tuberculosis. J Clin Microbiol. 48,4337-9.

Muñoz-Mendonza, M., de Juan, L., Menéndez, S., Ocampo, O., Mourelo, J., Sáez, J., Domínguez, L., Gortázar, C., García Marín, JF., Balseiro, A., 2012. Tuberculosis due to Mycobacterium bovis and Mycobacterium caprae in sheep. Vet J. 191, 267-69.

Muñoz-Mendonza, M., Romero, B., del Cerro, A., Gortázar, C., García-Marín, JF., Menéndez, S., Mourelo, L., de Juan, L., Saéz, JL., Delahay, RJ., Balseiro, A., 2016. Sheep as a Potential Source of Bovine TB: Epidemiology, Pathology and Evaluation of Diagnostic Techniques. Transbound Emerg Dis. 63, 635-646Navarro, Y., Herranz, M., Pérez-Lago, L., Martínez, M., Ruiz-Serrano, MJ., Bouza, E., Bouza, E., García de Viedma, D., 2011. Systematic Survey of Clonal Complexity 
in Tuberculosis at a Populational Level and Detailed Characterization of the Isolates Involved. J

$592 \quad$ Clin Microbiol 49, 4131-37.

593 Navarro, Y., Herranz, M., Romero, B., Bouza, E., Domínguez, L., de Juan, L., García-de-Viedma, 594 D., 2014. High-throughput multiplex MIRU-VNTR typing of Mycobacterium bovis. Res. Vet. Sci. $59596,422-25$.

596 Navarro, Y., Romero, B., Bouza, E., Domínguez, L., de Juan, L., García-de-Viedma, D., 2016. 597 Detailed Chronological Analysis of Microevolution Events in Herds Infected Persistently by $598 \quad$ Mycobacterium bovis. Vet Microbiol 183, 97-102.

599 Pesciaroli, M., Alvarez, J., Boniotti, MB., Cagiola, M., Di Marco, V., Marianelli, C., Pacciarini, M., 600 Pasquali, P., 2014. Tuberculosis in domestic animal species. Res. Vet. Sci. 97, 78-85.

601 Prodinger, WM., Brandstätter, A., Naumann, L., Pacciarini, M., Kubica, T., Boschiroli, ML., Aranaz, 602 A., Nagy, G., Cvetnic, Z., Ocepek, M., Skrypnyk, A., Erler, W., Niemann, S., Pavlik, I., Moser, I., 603 2005. Characterization of Mycobacterium caprae Isolates from Europe by Mycobacterial 604 Interspersed Repetitive Unit Genotyping. J Clin Microbiol. 43, 4984-92.

605 Rodríguez, E., Sánchez, LP., Pérez, S., Herrera, L., Jiménez, MS., Samper, S., Iglesias, MJ., 2009. 606 Human Tuberculosis due to Mycobacterium bovis and M. caprae in Spain, 2004-2007. Int J Tuberc 607 Lung Dis. 13,1536-41.

608 Rodríguez, S., Bezos, J., Romero, B., de Juan, L., Álvarez, J., Castellanos, E., Moya, N., Lozano, F., 609 Javed, MT., Sáez-Llorente, JL., Liébana, E., Mateos, A., Domínguez, L., Aranaz, A., 2011. 610 Mycobacterium caprae Infection in Livestock and Wildlife, Spain. Emerg Infect Dis. 17,532-5.

611 Schoepf, K., Prodinger, WM., Glawischnig, W., Hofer, E., Revilla-Fernandez, S., Hofrichter, J., Fritz, 612 J., Köfer, J., Schmoll, F., 2012. A Two-Years' Survey on the Prevalence of Tuberculosis Caused 613 by Mycobacterium caprae in Red Deer (Cervus elaphus) in the Tyrol, Austria. ISRN Vet Sci. 614 doi:10.5402/2012/245138. 
615 Skuce, RA., McCorry, TP., McCarroll, JF., Roring, SM., Scott, AN., Brittain, D., Hughes, SL., 616 Hewinson, RG., Neill, SD., 2000. Discrimination of Mycobacterium tuberculosis complex bacteria 617 using novel VNTR-PCR targets. Microbiol. 148, 519-28.

618 Shamputa, IC., Jugheli, L., Sadradze, N., Willery, E., Portaels, F., Supply, P., Rigouts, L., 2006. 619 Mixed infection and clonal representativeness of a single sputum sample in tuberculosis patients 620 from a penitentiary hospital in Georgia. Respir Res. 17, 7:99.

621 Smith, N. H., Kremer, K., Inwald, J., Dale, J., Driscoll, J. R., Gordon, S. V., van Soolingen, D., 622 Hewinson, RG., Smith, JM.,2006. Ecotypes of the Mycobacterium tuberculosis complex. J Theor 623 Biol. 239, 220-225.

624 Supply, P., Magdalena, J., Himpens, S., Locht, C., 1997. Identification of a novel intergenic repetitive 625 units in a mycobacterial two-component system operon. Mol Microbiol. 26, 911-1003.

626 Supply, P., Lesjean, S., Savine, E., Kremer, K., van Soolingen, D., Locht, C., 2001. Automated high627 throughput genotyping for study of global epidemiology of Mycobacterium tuberculosis based on 628 mycobacterial interspersed repetitive units. J Clin Microbiol. 39, 3563-71.

629 Supply, P., Allix, C., Lesjean, S., Cardoso-Oelemann, M., Rüsch-Gerdes, S., Willery, E., Savine, E., 630 de Haas, P., van Deutekom, H., Roring, S., Bifani, P., Kurepina, N., Kreiswirth, B., Sola, C., 631 Rastogi, N., Vatin, V., Gutierrez, MC., Fauville, M., Niemann, S., Skuce, R., Kremer, K., Locht, 632 C., van Soolingen, D., 2006. Proposal for Standardization of Optimized Mycobacterial 633 Interspersed Repetitive Unit Variable-Number Tandem Repeat Typing of Mycobacterium 634 tuberculosis. J Clin Microbiol. 44, 4498-4510. 
Table 1. Systematic MIRU-VNTR typing of $M$. caprae isolates.

\begin{tabular}{|c|c|c|c|c|c|c|c|c|c|c|c|c|c|c|c|c|}
\hline \multirow{2}{*}{$\begin{array}{c}\text { Geographic } \\
\text { location }\end{array}$} & \multirow[b]{2}{*}{ Herd } & \multirow[b]{2}{*}{ Host (ID) } & \multicolumn{8}{|c|}{ MIRU-VNTR allelic profile } & \multirow{2}{*}{$\begin{array}{l}\text { MIRU- } \\
\text { VNTR } \\
\text { type }\end{array}$} & \multirow{2}{*}{$\begin{array}{l}\text { Clonal } \\
\text { Complex }\end{array}$} & \multirow{2}{*}{$\begin{array}{c}\text { No } \\
\text { genotypic } \\
\text { profiles }\end{array}$} & \multirow{2}{*}{$\begin{array}{l}\text { Nature of } \\
\text { outbreak }\end{array}$} & \multirow{2}{*}{$\begin{array}{c}\text { Year } \\
\text { isolation }\end{array}$} & \multirow[b]{2}{*}{ Source } \\
\hline & & & $\begin{array}{l}\text { VNTR } \\
3232\end{array}$ & $\begin{array}{c}\text { ETR- } \\
\text { A }\end{array}$ & $\begin{array}{c}\text { ETR- } \\
\text { B }\end{array}$ & $\begin{array}{c}\text { ETR- } \\
\text { C }\end{array}$ & $\begin{array}{c}\text { QUB } \\
11 a\end{array}$ & $\begin{array}{l}\text { QUB } \\
11 \mathrm{~b}\end{array}$ & $\begin{array}{c}\text { MIRU } \\
4\end{array}$ & $\begin{array}{c}\text { MIRU } \\
26\end{array}$ & & & & & & \\
\hline \multirow{16}{*}{ BG } & BG2 & B3 & 5 & 4 & 3 & 4 & 7 & 2 & 4 & 6 & M120 & - & 1 & & 2007 & $\begin{array}{l}\text { Cunha et } \\
\text { al., } 2012\end{array}$ \\
\hline & \multirow{7}{*}{ BG1 } & G8, G10 & 5 & 5 & 3 & 4 & 7 & 4 & 4 & 6 & M116 & - & 2 & \multirow{7}{*}{$\begin{array}{l}\text { Heterogeneous } \\
\text { (7 genotypes) }\end{array}$} & \multirow{4}{*}{2008} & \multirow{4}{*}{$\begin{array}{l}\text { Cunha et } \\
\text { al., } 2012\end{array}$} \\
\hline & & G9 & 5 & 5 & 3 & 4 & 7 & 4 & - & 6 & M117 & - & 1 & & & \\
\hline & & G11 & 5 & 5 & 3 & 4 & 7 & 4 & - & 6 & M117' & - & 1 & & & \\
\hline & & G12 & 5 & 3 & 5 & 4 & 7 & 4 & - & 2 & M119 & - & 1 & & & \\
\hline & & G13 & 4 & 5 & 3 & 4 & 7 & 4 & 4 & 5 & M132 & 2 & 1 & & \multirow{3}{*}{2010} & \multirow{3}{*}{$\begin{array}{l}\text { This } \\
\text { study }\end{array}$} \\
\hline & & & 4 & 5 & 3 & 4 & 7 & 4 & 3 & 5 & M133 & 2 & 1 & & & \\
\hline & & G15 & 4 & 5 & 3 & 4 & 7 & 4 & 4 & 5 & M132 & 2 & 1 & & & \\
\hline & BG3 & G21 & $\begin{array}{l}4 \\
4\end{array}$ & $\begin{array}{l}5 \\
5\end{array}$ & $\begin{array}{l}3 \\
3\end{array}$ & $\begin{array}{l}4 \\
4\end{array}$ & $\begin{array}{l}7 \\
7\end{array}$ & $\begin{array}{l}4 \\
4\end{array}$ & $\begin{array}{l}4 \\
3\end{array}$ & $\begin{array}{l}5 \\
5\end{array}$ & $\begin{array}{l}\text { M132 } \\
\text { M133 }\end{array}$ & $\begin{array}{l}2 \\
2\end{array}$ & $\begin{array}{l}1 \\
1\end{array}$ & & 2010 & $\begin{array}{l}\text { This } \\
\text { study }\end{array}$ \\
\hline & BG4 & B14 & $\begin{array}{l}4 \\
4\end{array}$ & $\begin{array}{l}5 \\
5\end{array}$ & $\begin{array}{l}3 \\
3\end{array}$ & $\begin{array}{l}4 \\
4\end{array}$ & $\begin{array}{l}7 \\
7\end{array}$ & $\begin{array}{l}4 \\
4\end{array}$ & $\begin{array}{l}4 \\
3\end{array}$ & $\begin{array}{l}5 \\
5\end{array}$ & $\begin{array}{l}\text { M132 } \\
\text { M133 }\end{array}$ & $\begin{array}{l}2 \\
2\end{array}$ & $\begin{array}{l}1 \\
1\end{array}$ & & 2010 & $\begin{array}{l}\text { This } \\
\text { study }\end{array}$ \\
\hline & BG5 & S1 & 4 & 5 & 3 & 4 & 7 & 4 & 4 & 5 & M132 & 2 & 1 & & 2010 & $\begin{array}{l}\text { This } \\
\text { study }\end{array}$ \\
\hline & $\mathrm{N} / \mathrm{A}$ & G14 & $\begin{array}{l}4 \\
4\end{array}$ & $\begin{array}{l}5 \\
5\end{array}$ & $\begin{array}{l}3 \\
3\end{array}$ & $\begin{array}{l}4 \\
4\end{array}$ & $\begin{array}{l}7 \\
7\end{array}$ & $\begin{array}{l}4 \\
4\end{array}$ & $\begin{array}{l}4 \\
3\end{array}$ & $\begin{array}{l}5 \\
5\end{array}$ & $\begin{array}{l}\text { M132 } \\
\text { M133 }\end{array}$ & $\begin{array}{l}2 \\
2\end{array}$ & $\begin{array}{l}1 \\
1\end{array}$ & & 2010 & $\begin{array}{l}\text { This } \\
\text { study }\end{array}$ \\
\hline & $N / A$ & G16 & $\begin{array}{l}4 \\
4\end{array}$ & $\begin{array}{l}5 \\
5\end{array}$ & $\begin{array}{l}3 \\
3\end{array}$ & $\begin{array}{l}4 \\
4\end{array}$ & $\begin{array}{l}7 \\
7\end{array}$ & $\begin{array}{l}4 \\
4\end{array}$ & $\begin{array}{l}4 \\
3\end{array}$ & $\begin{array}{l}5 \\
5\end{array}$ & $\begin{array}{l}\text { M132 } \\
\text { M133 }\end{array}$ & $\begin{array}{l}2 \\
2\end{array}$ & $\begin{array}{l}1 \\
1\end{array}$ & & 2010 & $\begin{array}{l}\text { This } \\
\text { study }\end{array}$ \\
\hline & $\mathrm{N} / \mathrm{A}$ & G18 & $\begin{array}{l}4 \\
4\end{array}$ & $\begin{array}{l}5 \\
5\end{array}$ & $\begin{array}{l}3 \\
3\end{array}$ & $\begin{array}{l}4 \\
4\end{array}$ & $\begin{array}{l}7 \\
7\end{array}$ & $\begin{array}{l}4 \\
4\end{array}$ & $\begin{array}{l}4 \\
3\end{array}$ & $\begin{array}{l}5 \\
5\end{array}$ & $\begin{array}{l}\text { M132 } \\
\text { M133 }\end{array}$ & $\begin{array}{l}2 \\
2\end{array}$ & $\begin{array}{l}1 \\
1\end{array}$ & & 2010 & $\begin{array}{l}\text { This } \\
\text { study }\end{array}$ \\
\hline & N/A & G19 & $\begin{array}{l}4 \\
4\end{array}$ & $\begin{array}{l}5 \\
5\end{array}$ & $\begin{array}{l}3 \\
3\end{array}$ & $\begin{array}{l}4 \\
4\end{array}$ & $\begin{array}{l}7 \\
7\end{array}$ & $\begin{array}{l}4 \\
4\end{array}$ & $\begin{array}{l}4 \\
3\end{array}$ & $\begin{array}{l}5 \\
5\end{array}$ & $\begin{array}{l}\text { M132 } \\
\text { M133 }\end{array}$ & $\begin{array}{l}2 \\
2\end{array}$ & $\begin{array}{l}1 \\
1\end{array}$ & & 2010 & $\begin{array}{l}\text { This } \\
\text { study }\end{array}$ \\
\hline & $\mathrm{N} / \mathrm{A}$ & G20 & $\begin{array}{l}4 \\
4\end{array}$ & $\begin{array}{l}5 \\
5\end{array}$ & $\begin{array}{l}3 \\
3\end{array}$ & $\begin{array}{l}4 \\
4\end{array}$ & $\begin{array}{l}7 \\
7\end{array}$ & $\begin{array}{l}4 \\
4\end{array}$ & $\begin{array}{l}4 \\
3\end{array}$ & $\begin{array}{l}5 \\
5\end{array}$ & $\begin{array}{l}\text { M132 } \\
\text { M133 }\end{array}$ & $\begin{array}{l}2 \\
2\end{array}$ & $\begin{array}{l}1 \\
1\end{array}$ & & 2010 & $\begin{array}{l}\text { This } \\
\text { study }\end{array}$ \\
\hline
\end{tabular}




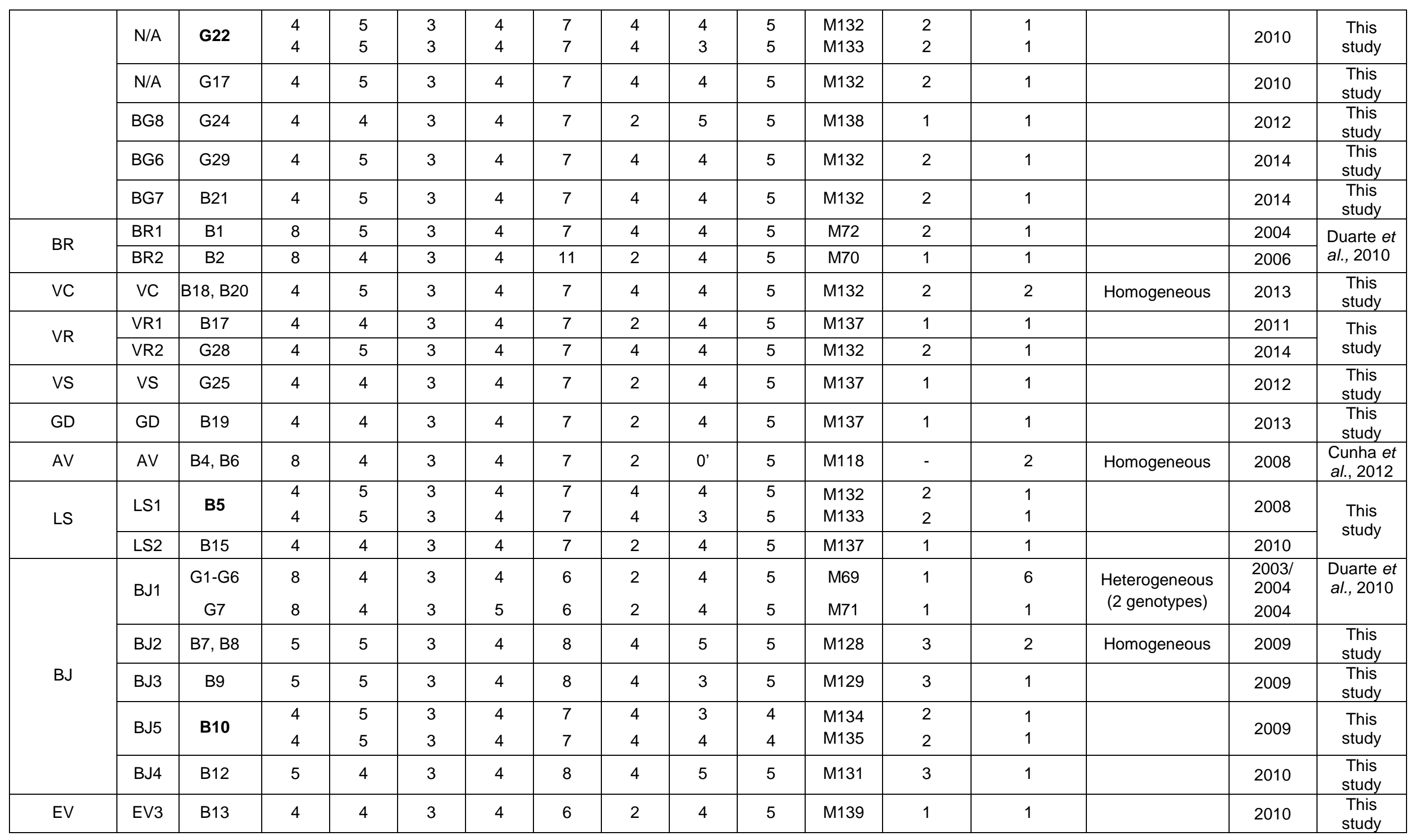




\begin{tabular}{|c|c|c|c|c|c|c|c|c|c|c|c|c|c|c|c|c|}
\hline & \multirow{2}{*}{ EV1 } & \multirow{2}{*}{$\begin{array}{l}\text { G23 } \\
\text { G26 }\end{array}$} & \multirow{2}{*}{$\begin{array}{l}4 \\
4 \\
4\end{array}$} & \multirow{2}{*}{$\begin{array}{l}4 \\
4 \\
4\end{array}$} & \multirow{2}{*}{$\begin{array}{l}3 \\
3 \\
3\end{array}$} & \multirow{2}{*}{$\begin{array}{l}4 \\
4 \\
4\end{array}$} & \multirow{2}{*}{$\begin{array}{l}7 \\
7 \\
7\end{array}$} & \multirow{2}{*}{$\begin{array}{l}2 \\
2 \\
2\end{array}$} & \multirow{2}{*}{$\begin{array}{l}3 \\
4 \\
4\end{array}$} & \multirow{2}{*}{$\begin{array}{l}5 \\
5 \\
5\end{array}$} & \multirow{2}{*}{$\begin{array}{l}\text { M136 } \\
\text { M137 } \\
\text { M137 }\end{array}$} & \multirow{2}{*}{$\begin{array}{l}1 \\
1 \\
1\end{array}$} & $\begin{array}{l}1 \\
1\end{array}$ & \multirow{2}{*}{$\begin{array}{c}\text { Heterogeneous } \\
\text { (3 genotypes) }\end{array}$} & \multirow{2}{*}{$\begin{array}{l}2012 \\
2013\end{array}$} & \multirow[t]{2}{*}{$\begin{array}{l}\text { This } \\
\text { study }\end{array}$} \\
\hline & & & & & & & & & & & & & 1 & & & \\
\hline & EV2 & G27 & 4 & 4 & 3 & 4 & 7 & 2 & 4 & 5 & M137 & 1 & 1 & & 2013 & $\begin{array}{l}\text { This } \\
\text { study }\end{array}$ \\
\hline \multirow{2}{*}{$A Z$} & $A Z 1$ & B11 & 5 & 4 & 3 & 4 & 8 & 2 & 5 & 5 & M130 & 3 & 1 & & 2009 & $\begin{array}{l}\text { This } \\
\text { study }\end{array}$ \\
\hline & $A Z 2$ & B16 & 2 & 4 & 3 & 4 & 1 & 2 & 4 & 5 & M140 & - & 1 & & 2010 & $\begin{array}{l}\text { This } \\
\text { study }\end{array}$ \\
\hline \multirow{2}{*}{ CB } & \multirow{2}{*}{$\mathrm{N} / \mathrm{A}$} & WB2 & 5 & 5 & 4 & 2 & 12 & 2 & 3 & 6 & M122 & - & 1 & - & 2008 & $\begin{array}{l}\text { Duarte et } \\
\text { al., } 2010\end{array}$ \\
\hline & & WB3 & 4 & 4 & 3 & 4 & 7 & 2 & 4 & 5 & M137 & 1 & 1 & - & 2009 & $\begin{array}{c}\text { This } \\
\text { study }\end{array}$ \\
\hline$P G$ & $\mathrm{~N} / \mathrm{A}$ & WB4 & 4 & 4 & 3 & 4 & 7 & 2 & 4 & 5 & M137 & 1 & 1 & - & 2014 & $\begin{array}{l}\text { This } \\
\text { study }\end{array}$ \\
\hline Total & $\begin{array}{l}\mathrm{n}=35 \\
\text { herds }\end{array}$ & $\begin{array}{c}\mathrm{n}_{(\mathrm{G})}=29 \\
\mathrm{n}_{(\mathrm{S})}=1 \\
\mathrm{n}_{(\mathrm{B})}=21 \\
\mathrm{n}_{(\mathrm{WB})}=4\end{array}$ & & & & & & & & & $\begin{array}{l}\mathrm{n}=24 \\
\text { MIRU } \\
\text { types }\end{array}$ & $n=3$ & $\begin{array}{c}\mathrm{n}=67 \\
\text { genotypic } \\
\text { profiles }\end{array}$ & & & \\
\hline
\end{tabular}

Legend: 0' means the absence of a 53 pb additional sequence in MIRU 4 locus; - indicates an undetermined allele; N/A - not available.

Host: G - goat, B - bovine, S - sheep and WB - wild boar; animals harbouring two genotypic profiles are marked in bold;

Geographic location: AV - Aveiro, AZ - Azores islands, BR - Braga, BJ - Beja, BG - Bragança, CB - Castelo Branco, EV - Évora, GD - Guarda, LS - Lisboa, PG - Portalegre, VC

- Viana do Castelo, VR - Vila Real and VS - Viseu. 


\section{Figure captions}
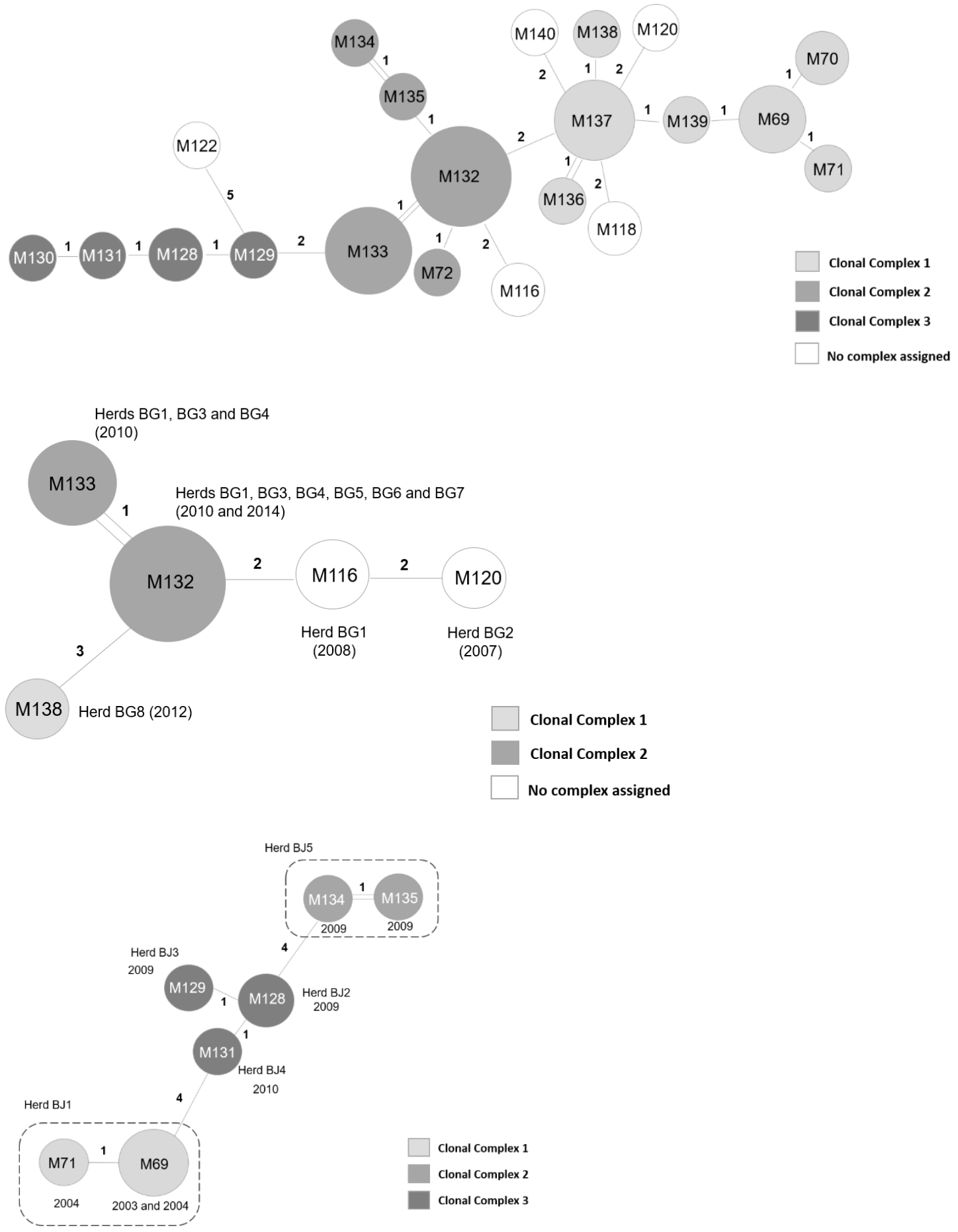

Figure 1. Minimum spanning tree (MST) of (a) the complete M. caprae genotypic profiles $(n=64)$; (b) the 14 genotypic profiles from Bragança district; (c) the 15 genotypic profiles from Beja district. MST was based only on complete MIRU-VNTR types, obtained with the single locus variant analysis, using the online application MIRU-VNTRplus. Circle size is proportional to the number of genotypic profiles within each MIRU type; the numbers between two circles represent the number of differences between those MIRU types. Each clonal complex is identified in grey scale as indicated. M117, M117' and M119 
are not represented once the number of repetitions for MIRU4 could not be determined. MIRU types of intra-host clonal variants are connected by double dashes.

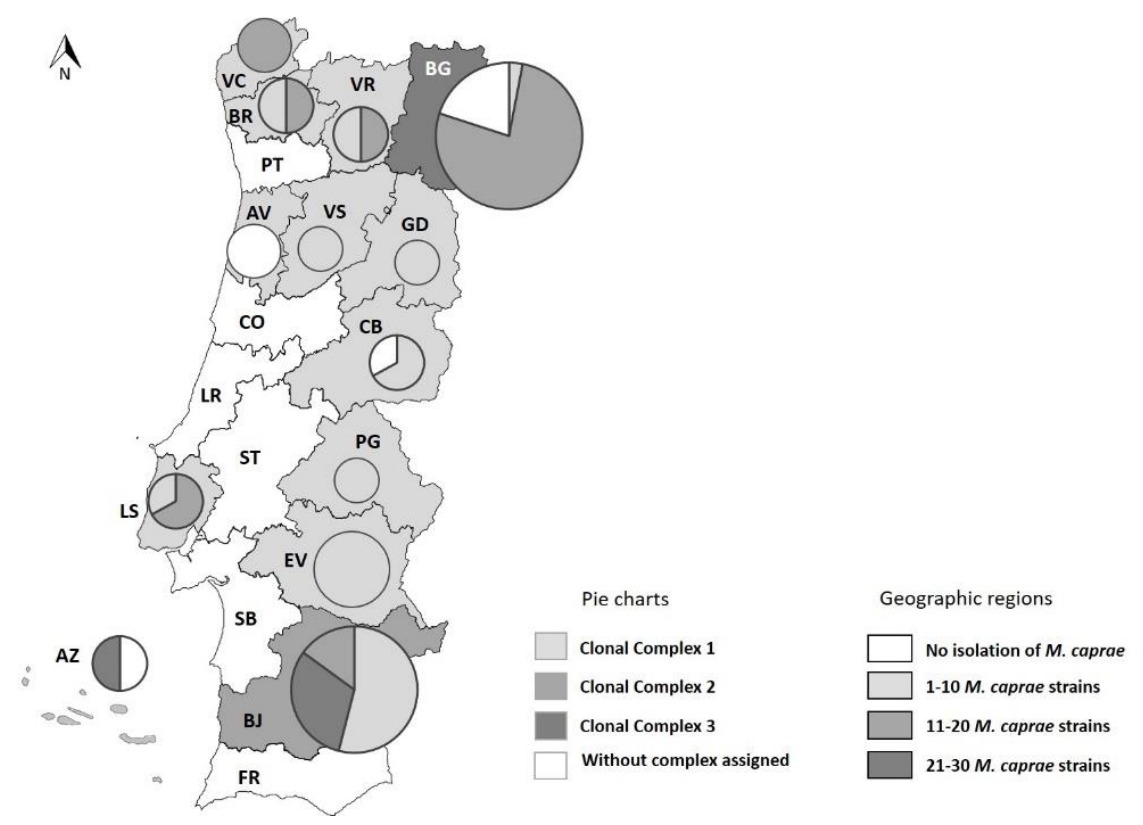

Figure 2. Distribution and frequency of each clonal complex per geographic location (district as administrative region).

The pie charts show the proportion of $M$. caprae genotypic profiles grouped by clonal complex. AV - Aveiro, AZ - Açores, BR - Braga, BJ - Beja, BG - Bragança, CB - Castelo Branco, CO - Coimbra, EV - Évora, FR - Faro, LR - Leiria, ST - Santarém, SB - Setúbal, GD - Guarda, LS - Lisboa, PG Portalegre, PT - Porto, VC - Viana do Castelo, VR - Vila Real and VS - Viseu 


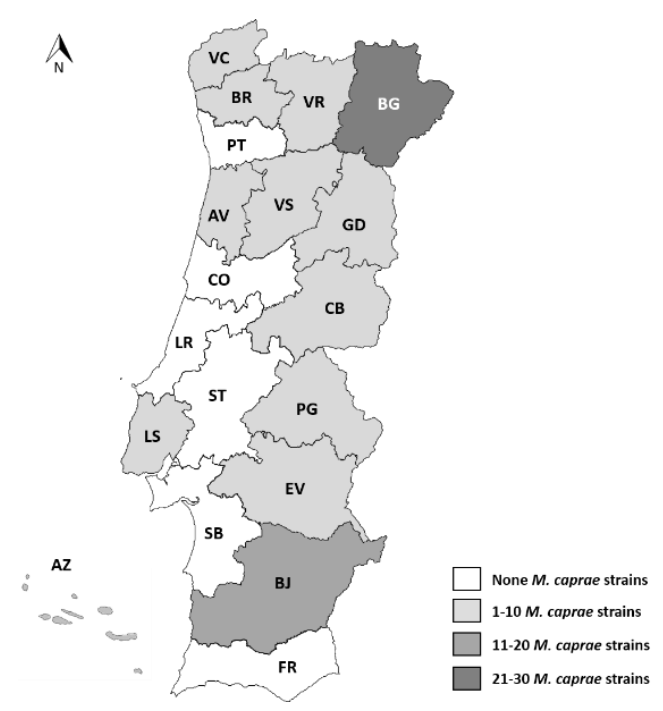

Supplementary Figure 1. The geographic distribution and number of $M$. caprae strains from the 55 animals under analysis across the districts of mainland Portugal and Azores islands is evidenced in grey scale. Legend: AV - Aveiro, AZ - Açores, BR - Braga, BJ - Beja, BG - Bragança, CB - Castelo Branco, CO - Coimbra, EV - Évora, FR - Faro, LR - Leiria, ST - Santarém, SB - Setúbal, GD - Guarda, LS Lisboa, PG - Portalegre, PT - Porto, VC - Viana do Castelo, VR - Vila Real and VS - Viseu. 


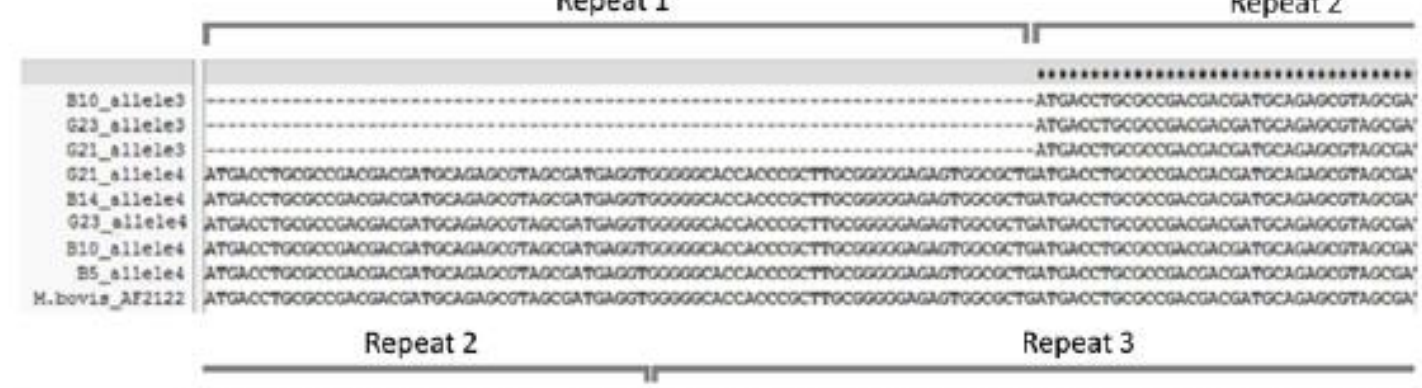

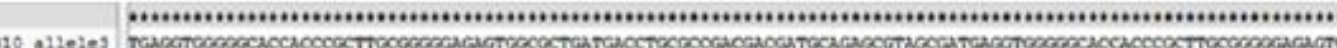

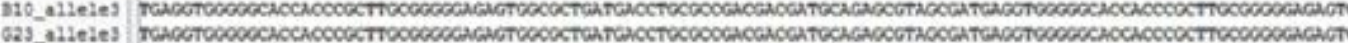

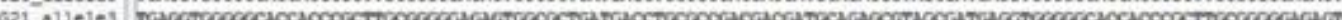

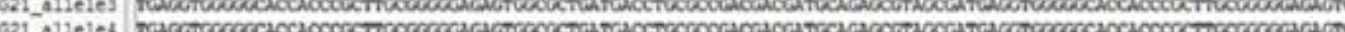
621_-

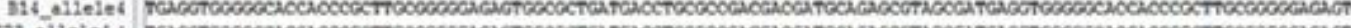
72. -

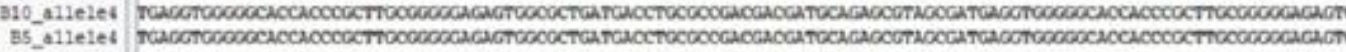

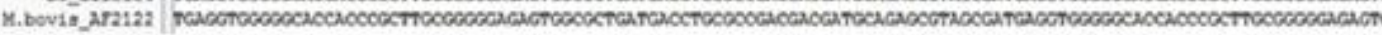

Repeat 3

Repeat 4

$53 \mathrm{pb}$

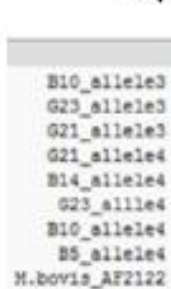
(5sp

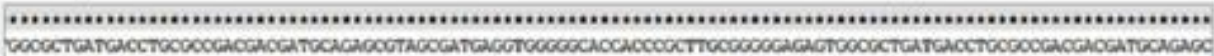

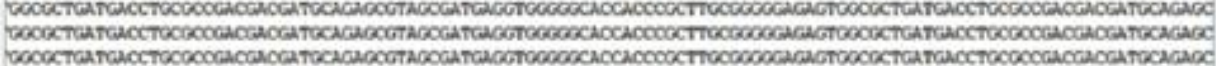

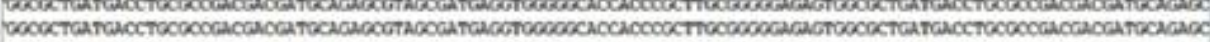

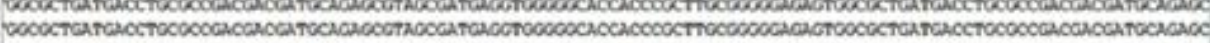

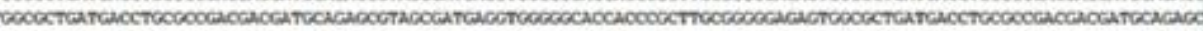

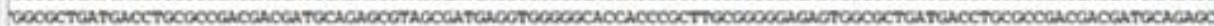

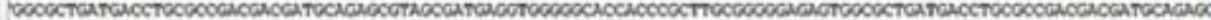

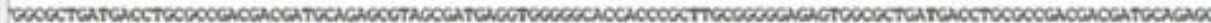

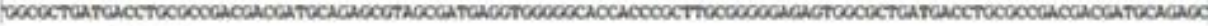

$53 \mathrm{pb}$

\begin{tabular}{|c|c|}
\hline & 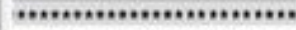 \\
\hline 510_allele3 & TTACCGATCAOCAOCa CTCCCCCTC \\
\hline 023 alleies & 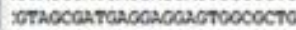 \\
\hline 021.011e1e9 & 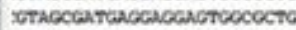 \\
\hline 621_allelet & STACCGATCA CGAOCA GTOCCOCTC \\
\hline sid alleied & 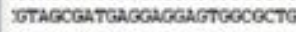 \\
\hline G23_a111ed & 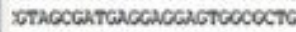 \\
\hline ato_allele4 & 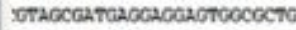 \\
\hline B5_a.11e1ed & 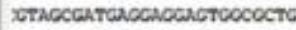 \\
\hline M.bevig_as2122 & 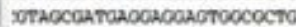 \\
\hline
\end{tabular}

Supplementary Figure 2. MIRU4 nucleotide sequence alignment of the reference strain $M$. bovis AF2122 and the sequences of allele 4 and allele 3 amplified from $M$. caprae DNA recovered from five different animals. The multiple sequence alignment was performed with ClustalX and each repeat motif of $77 \mathrm{bp}$ is indicated above 


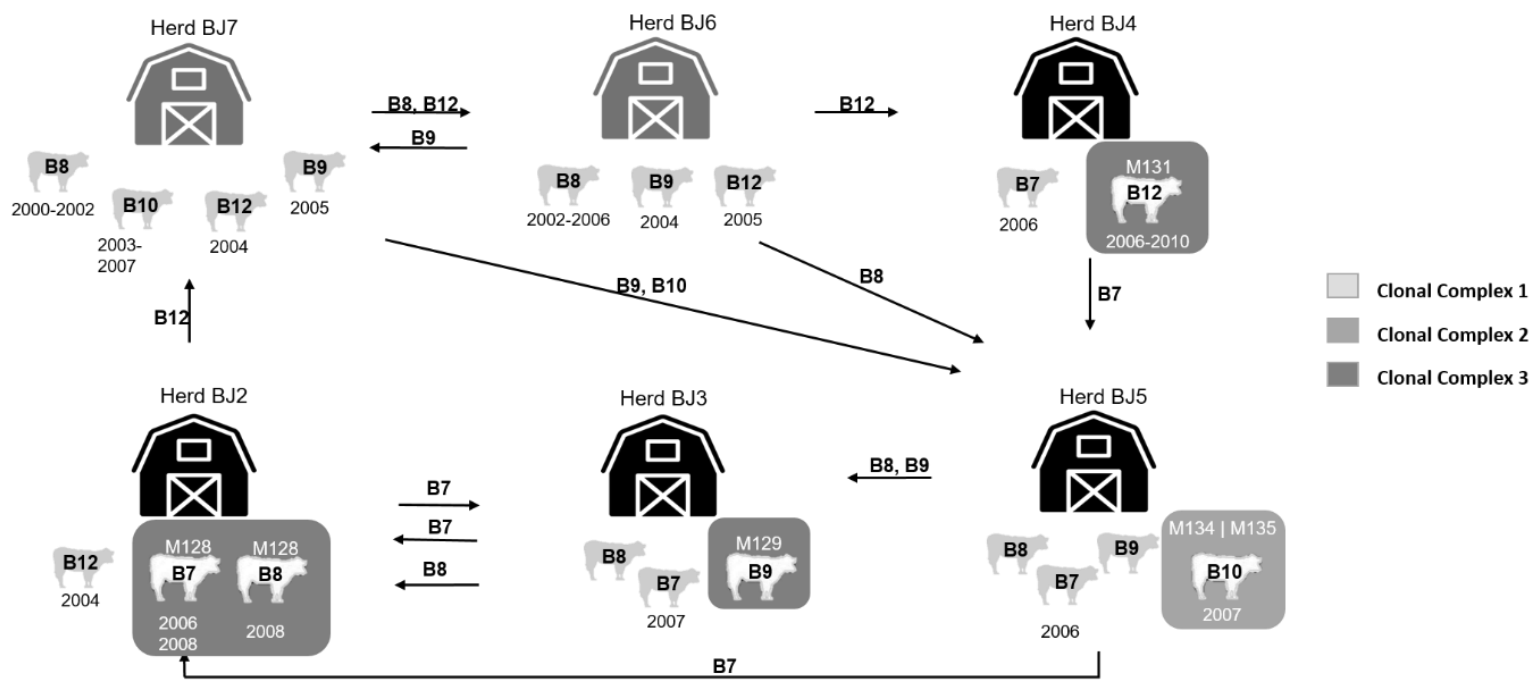

Supplementary Figure 3. Cattle circulation in six herds (BJ2-BJ7) from the district of Beja (BJ). Different animals are represented by their ID codes (B\#); arrows represent animal movement between herds; the time period (year) at which each animal or group of animals resided at a given herd is indicated. Light grey represents animal movement between herds and white represents the last stop (herd at time of death). The MIRU type of M. caprae isolate obtained at time of death is indicated for each animal. The shade of the grey box around each animal is representative of the respective clonal complex, as indicated. Attention to the movement of animal B7 that has two stays in herd BJ2, one in 2006 and another in 2008. 
Supplementary Table 1. Available epidemiological information of M. caprae infected animals.

\begin{tabular}{|c|c|c|c|c|c|c|c|c|c|}
\hline ID & Species & Gender & Herd type & $\begin{array}{c}\text { Herd } \\
\text { management }\end{array}$ & $\begin{array}{c}\text { Herd } \\
\text { dimension }\end{array}$ & Lesion type & MIRU type & $\begin{array}{c}\text { Geographic } \\
\text { location }\end{array}$ & Herd \\
\hline G1 & Goat & N/A & Mixed & N/A & $\mathrm{C}$ & N/A & M69 & $\mathrm{BJ}$ & BJ1 \\
\hline G2 & Goat & N/A & Mixed & N/A & $\mathrm{C}$ & N/A & M69 & BJ & BJ1 \\
\hline G3 & Goat & N/A & Single & N/A & $\mathrm{C}$ & N/A & M69 & BJ & BJ1 \\
\hline G4 & Goat & N/A & Single & N/A & $\mathrm{C}$ & N/A & M69 & BJ & BJ1 \\
\hline G5 & Goat & N/A & Single & N/A & $\mathrm{C}$ & N/A & M69 & BJ & BJ1 \\
\hline G6 & Goat & N/A & Single & N/A & $\mathrm{C}$ & N/A & M69 & BJ & BJ1 \\
\hline G7 & Goat & N/A & Single & N/A & $\mathrm{C}$ & N/A & M71 & BJ & BJ1 \\
\hline G8 & Goat & N/A & Single & N/A & $\mathrm{C}$ & N/A & M116 & BG & BG1 \\
\hline G9 & Goat & N/A & Single & N/A & $\mathrm{C}$ & N/A & M117 & BG & BG1 \\
\hline G10 & Goat & N/A & Single & N/A & $\mathrm{C}$ & N/A & M116 & BG & BG1 \\
\hline G11 & Goat & N/A & Single & N/A & $\mathrm{C}$ & N/A & M117' & BG & BG1 \\
\hline G12 & Goat & N/A & Single & N/A & $\mathrm{C}$ & N/A & M119 & BG & BG1 \\
\hline G13 & Goat & Male & Single & N/A & $\mathrm{C}$ & N/A & M132 and 133 & BG & BG1 \\
\hline G14 & Goat & Female & N/A & N/A & N/A & N/A & M132 and 133 & BG & N/A \\
\hline G15 & Goat & Female & Single & N/A & N/A & N/A & M132 & $\mathrm{BG}$ & BG1 \\
\hline G16 & Goat & N/A & N/A & N/A & N/A & N/A & M132 and 133 & BG & N/A \\
\hline G17 & Goat & N/A & N/A & N/A & N/A & N/A & M132 & $\mathrm{BG}$ & N/A \\
\hline G18 & Goat & N/A & N/A & N/A & N/A & N/A & M132 and 133 & BG & N/A \\
\hline G19 & Goat & N/A & N/A & N/A & N/A & N/A & M132 and 133 & $\mathrm{BG}$ & N/A \\
\hline G20 & Goat & N/A & N/A & N/A & N/A & N/A & M132 and 133 & BG & N/A \\
\hline G21 & Goat & Female & Mixed & Extensive & $\mathrm{B}$ & N/A & M132 and 133 & $\mathrm{BG}$ & BG3 \\
\hline G22 & Goat & N/A & N/A & N/A & N/A & N/A & M132 and 133 & BG & N/A \\
\hline G23 & Goat & Female & Single & Intensive & $\mathrm{C}$ & III & M137 and 140 & $\mathrm{EV}$ & EV1 \\
\hline G24 & Goat & Female & Single & Extensive & $\mathrm{C}$ & I & M138 & $\mathrm{BG}$ & BG8 \\
\hline G25 & Goat & Female & Single & Extensive & $\mathrm{C}$ & III & M137 & VS & VS \\
\hline G26 & Goat & Female & Single & Intensive & $\mathrm{C}$ & III & M137 & $\mathrm{EV}$ & EV1 \\
\hline
\end{tabular}




\begin{tabular}{|c|c|c|c|c|c|c|c|c|c|}
\hline G27 & Goat & Female & Single & Extensive & $\mathrm{C}$ & III & M137 & EV & EV2 \\
\hline G28 & Goat & Female & Single & Extensive & A & II & M132 & VR & VR2 \\
\hline G29 & Goat & Female & Single & Extensive & A & III & M132 & BG & BG6 \\
\hline B1 & Bovine & Female & Single & Intensive & N/A & N/A & M72 & BR & BR1 \\
\hline B2 & Bovine & Female & Single & Intensive & A & N/A & M70 & BR & BR2 \\
\hline B3 & Bovine & Female & Single & Extensive & A & N/A & M120 & BG & BG2 \\
\hline B4 & Bovine & Male & Mixed & Intensive & N/A & I & M118 & AV & AV \\
\hline B5 & Bovine & Male & Single & N/A & N/A & II & M132 and 133 & LS & LS1 \\
\hline B6 & Bovine & Male & Mixed & Intensive & N/A & I & M118 & AV & AV \\
\hline B7 & Bovine & Female & Single & N/A & B & I & M128 & BJ & BJ2 \\
\hline B8 & Bovine & Female & Single & N/A & B & I & M128 & BJ & BJ2 \\
\hline B9 & Bovine & Female & Single & N/A & B & N/A & M129 & BJ & $\mathrm{BJ} 3$ \\
\hline B10 & Bovine & Male & Single & N/A & B & N/A & M134 and 135 & BJ & BJ5 \\
\hline B11 & Bovine & Male & N/A & N/A & N/A & N/A & M130 & $\mathrm{AZ}$ & AZ1 \\
\hline B12 & Bovine & Female & Single & Extensive & B & II & M131 & BJ & BJ4 \\
\hline B13 & Bovine & Female & Single & Extensive & $\mathrm{C}$ & II & M139 & EV & EV3 \\
\hline B14 & Bovine & Female & Single & Extensive & A & N/A & M132 and 133 & $\mathrm{BG}$ & BG4 \\
\hline B15 & Bovine & Female & Mixed & N/A & B & II & M137 & LS & LS2 \\
\hline B16 & Bovine & Female & Mixed & N/A & N/A & N/A & M140 & $\overline{\mathrm{AZ}}$ & AZ2 \\
\hline B17 & Bovine & Male & N/A & N/A & N/A & N/A & M137 & VR & VR1 \\
\hline B18 & Bovine & Male & N/A & N/A & N/A & N/A & M132 & $\mathrm{VC}$ & $\mathrm{VC}$ \\
\hline B19 & Bovine & Female & Mixed & N/A & A & III & M137 & GD & GD \\
\hline B20 & Bovine & Male & Single & N/A & A & N/A & M132 & $\mathrm{VC}$ & $\mathrm{VC}$ \\
\hline B21 & Bovine & Female & Single & N/A & A & II & M132 & BG & BG7 \\
\hline S1 & Sheep & Female & Single & Extensive & $\mathrm{C}$ & N/A & M132 & BG & BG5 \\
\hline WB1 & $\begin{array}{l}\text { Wild } \\
\text { boar }\end{array}$ & N/A & N/A & N/A & N/A & N/A & M70 & $\mathrm{CB}$ & N/A \\
\hline WB2 & $\begin{array}{l}\text { Wild } \\
\text { boar }\end{array}$ & N/A & N/A & N/A & N/A & II & M122 & $\mathrm{CB}$ & N/A \\
\hline
\end{tabular}




\begin{tabular}{|c|c|c|c|c|c|c|c|c|c|}
\hline WB3 & $\begin{array}{l}\text { Wild } \\
\text { boar }\end{array}$ & N/A & N/A & N/A & N/A & II & M137 & CB & N/A \\
\hline WB4 & $\begin{array}{l}\text { Wild } \\
\text { boar }\end{array}$ & N/A & N/A & N/A & N/A & II & M137 & PG & N/A \\
\hline
\end{tabular}

Legend: N/A: not available

Herd dimension: type A, less than 50 animals; type B, between 50 and 150 animals; and type C, more than 150 animals.

Lesion type: type I "caseous granulomatous lesions", type II “caseous granulomatous lesions with calcification" and type III “caseous granulomatous lesions with cavitation". Geographic location: AV - Aveiro, AZ - Azores islands, BR - Braga, BJ - Beja, BG - Bragança, CB - Castelo Branco, EV - Évora, GD - Guarda, LS - Lisboa, PG - Portalegre, VC - Viana do Castelo, VR - Vila Real and VS - Viseu.

Supplementary Table 2a. Data introduced in SPSS for statistical analysis (association between clonal complex and host species).

\begin{tabular}{|l|l|l|l|l|}
\hline Clonal complex & Bovine & Caprine & Wild boar & Ovine \\
\hline CC1 & 6 & 13 & 3 & 0 \\
\hline CC2 & 11 & 20 & 0 & 1 \\
\hline CC3 & 5 & 0 & 0 & 0 \\
\hline Without complex & 2 & 2 & 1 & 0 \\
\hline
\end{tabular}

Supplementary Table 2b. Data introduced in SPSS for statistical analysis (association between clonal complex and geographic location - NUTS).

\begin{tabular}{|l|l|l|l|l|}
\hline Clonal complex & Alentejo & Azores & Center & North \\
\hline CC1 & 13 & 0 & 3 & 6 \\
\hline CC2 & 2 & 0 & 4 & 26 \\
\hline CC3 & 4 & 1 & 0 & 0 \\
\hline Without complex & 0 & 1 & 1 & 3 \\
\hline
\end{tabular}

Supplementary Table 2c. Data introduced in SPSS for statistical analysis (association between clonal complex and geographic location - districts). 


\begin{tabular}{|l|l|l|l|l|l|l|l|l|l|l|l|l|l|}
\hline $\begin{array}{l}\text { Clonal } \\
\text { complex }\end{array}$ & AV & AZ & BR & BJ & BG & CB & EV & GD & LS & PG & VC & VR & VS \\
\hline CC1 & 0 & 0 & 2 & 7 & 1 & 2 & 5 & 1 & 1 & 1 & 0 & 1 & 1 \\
\hline CC2 & 2 & 0 & 0 & 2 & 23 & 0 & 0 & 0 & 2 & 0 & 2 & 1 & 0 \\
\hline CC3 & 0 & 1 & 0 & 4 & 0 & 0 & 0 & 0 & 0 & 0 & 0 & 0 & 0 \\
\hline $\begin{array}{l}\text { Without } \\
\text { complex }\end{array}$ & 0 & 1 & 0 & 0 & 3 & 1 & 0 & 0 & 0 & 0 & 0 & 0 & 0 \\
\hline
\end{tabular}

Legend: AV - Aveiro, AZ - Açores, BR - Braga, BJ - Beja, BG - Bragança, CB - Castelo Branco, CO - Coimbra, EV - Évora, FR - Faro, LR - Leiria, ST - Santarém, SB Setúbal, GD - Guarda, LS - Lisboa, PG - Portalegre, PT - Porto, VC - Viana do Castelo, VR - Vila Real and VS - Viseu

Supplementary Table 2d. Data introduced in SPSS for statistical analysis (association between clonal complex and time period).

\begin{tabular}{|l|l|l|l|}
\hline Clonal complex & Period 1 & Period 2 & Period 3 \\
\hline CC1 & 10 & 3 & 9 \\
\hline CC2 & 0 & 27 & 5 \\
\hline CC3 & 0 & 5 & 0 \\
\hline Without complex & 0 & 5 & 0 \\
\hline
\end{tabular}

Legend: Time period: period 1 between 2003 and 2006, period 2 between 2007 and 2010, and period 3 between 2011 and 2014. 
